\title{
Evaluation of outcome of pregnancy in placenta accreta spectrum
}

\author{
Uma Veludandi*, B. Aruna Suman, S. Nagamani, Medha Hothur
}

Department of Obstetrics and Gynaecology, MGMH, OMC Petlaburz, Hyderabad, Telangana, India

Received: 11 August 2021

Accepted: 25 August 2021

\author{
*Correspondence: \\ Dr. Uma Veludandi, \\ E-mail: veludandiuma1966@gmail.com
}

Copyright: () the author(s), publisher and licensee Medip Academy. This is an open-access article distributed under the terms of the Creative Commons Attribution Non-Commercial License, which permits unrestricted non-commercial use, distribution, and reproduction in any medium, provided the original work is properly cited.

\begin{abstract}
Background: Aim of the study was to evaluate the outcome of pregnancy in placenta accrete spectrum in third trimester pregnancy at tertiary care centre

Methods: This hospital based retrospective study was carried out from 2017 to 2019 . The case records of all women identified as placenta accrete spectrum from the hospital registers were retrieved. A total of 166 patients with the diagnosis of placenta accrete spectrum were included in the study.

Results: The incidence of morbidly adherent placenta is 5 per 10,000 deliveries with mean age being 32.4 \pm 4.2 (23-39) years. and showed its relation with risk factors such as previous caesarean section (CS), placenta praevia and multiparity. The mean duration of MICU stay in placenta previa was 6.7 \pm 1.9 days (range 2-12 days). With complications in 18 cases of which urinary bladder injury (3\%), infection (9\%), PPH and coagulopathy (4.2\%). The placenta was removed successfully in 141 while 25 cases had caesarean hysterectomy (2.4\%). In total 166 cases 26 $(16.8 \%)$ cases are intrauterine device (IUD) and still births. 5 (3\%) cases are very low birth weight, 24 cases (14.5\%) are low birth weight babies, $76(45.8 \%)$ cases had neonatal intensive care unit (NICU) admissions followed by 10 (6\%) cases with $<5$ APGAR score.

Conclusions: Placenta accreta spectrum can be identified antenatally with a high index of suspicion in the presence of known risk factors and proper radiological studies, allowing for planned attempts to avoid life-threatening haemorrhage and caesarean hysterectomy.
\end{abstract}

Keywords: Placenta accreta spectrum, Haemorrhage, Caesarean hysterectomy

\section{INTRODUCTION}

The placenta accreta spectrum, formerly known as morbidly adherent placenta, refers to the range of pathologic adherence of the placenta, which includes placenta accreta, increta and percreta. It was reported as 1:30,000 deliveries in 1950 and the incidence of morbidly adherent placenta has increased 10 -fold in the past 50 years, current frequency- 1 in 2500 deliveries because of alarming increase in cesarean section rates. Severe and even life-threatening haemorrhage, which frequently necessitates blood transfusion, can result in maternal morbidity and fatality. Women with morbidly adherent placenta spectrum have a higher risk of maternal death. morbidly adherent placenta has taken epidemic proportions of late which parallel's the rise in cesarean deliveries. Major risk factors are a history of placenta previa, previous CS, advanced maternal age, multiparity and a history of endo-uterine maneuvers. ${ }^{1}$

Placenta accreta spectrum is one of the most important causes of maternal mortality and morbidity in modern obstetrics with mortality as high as $7 \%$ and even higher in under-developed nations., ${ }^{2,3}$ Increased maternal morbidity is due to massive intrapartum or postpartum hemorrhage and its sequel namely, blood transfusions, coagulopathy, sepsis and multiorgan failure. Besides, it is currently the most common indication of emergency peripartum 
hysterectomy. Grey scale ultrasound is adequate in most cases for diagnosing the condition. However, MRI may be required in some cases especially in those with anterior placenta with bladder invasion and posterior placenta. It has been seen that antenatal diagnosis of this condition with planned elective delivery in a tertiary care set up with availability of multidisciplinary care can significantly improve maternal and fetal outcomes. ${ }^{4,5}$ The mainstay and standard treatment of this condition is peripartum hysterectomy after CS, without disturbing the placenta. Attempts at manual removal of placenta after cesarean in such cases can result in torrential hemorrhage with severe morbidity or mortality.

\section{METHODS}

This hospital based retrospective study was carried out from 2017 to 2019 in department of obstetrics and gynecology at maternity hospital as tertiary care center. The case records of all women identified as placenta accreta spectrum from the hospital registers were retrieved after approval of the institutional ethical committee to carry out this study. A total of 166 patients with the diagnosis of morbidly adherent placenta were included in the study. The criterion for diagnosis of morbidly adherent placenta was taken as manual removal of the placenta being partially or totally impossible or evidence of gross placental invasion at surgery or women with an ultrasound diagnosis confirmed by failed attempts to remove the placenta during the third stage of labor or histopathological confirmation of hysterectomy specimen.

The histopathological specimens were fixed in formalin, trimmed and stained with routine haematoxylin and eosin stain. Clinical and pathological correlation was done by obtaining relevant clinical details, radiological findings and histopathological diagnosis.

Maternal demographic data, mode of delivery was noted. From the operative notes, data on placental location, estimated blood loss, units of blood transfusion required and surgical procedure carried out to control bleeding was retrieved. Post-operative ICU admission, fetal outcome and maternal and fetal mortality was recorded.

\section{Statistical analysis}

Categorical variables were presented in number and percentage $(\%)$ and continuous variables were presented as mean \pm SD and median. The data was entered in MS excel spreadsheet and analysis was done using statistical package for social sciences (SPSS) version 21.0.

\section{RESULTS}

Among 28779 deliveries, 166 cases of morbidly adherent placenta with incidence of $0.5 \%$ i.e., 5:1000 births. Age range of patients was 21-37 years, mean age being $32.4 \pm 4.2(23-39)$ years.
Table 1: Baseline characteristics of present study.

\begin{tabular}{|llll|}
\hline Variable & & Number & Percentages (\%) \\
\hline \multirow{3}{*}{ Parity } & $1-2$ & 86 & 51.8 \\
\hline & $3-4$ & 67 & 40.3 \\
\cline { 2 - 4 } Previous CS & 1 & 50 & 7.8 \\
\cline { 2 - 4 } & 2 & 36 & 21.7 \\
\cline { 2 - 4 } & 4 & 65 & 39 \\
\hline $\begin{array}{l}\text { History of } \\
\text { placenta } \\
\text { previa }\end{array}$ & Yes & 20 & 9 \\
\hline $\begin{array}{l}\text { Age above } \\
\text { >35 years }\end{array}$ & & 40 & 24.4 \\
\hline
\end{tabular}

Most of the cases in study are multipara with at least one previous CS and no history of placenta previa.

Table 2: Regarding clinical, laboratory findings and post-operative morbidities in present study.

\begin{tabular}{|l|l|}
\hline Variable & Description \\
\hline Pre op. Hb (g/dl) & $11.1 \pm 0.23$ \\
\hline Post op. Hb (g/dl) & $9.3 \pm 0.3$ \\
\hline Estimated blood loss (L) & $2.73 \pm 1.12$ \\
\hline Blood transfusion (units) & $3.7 \pm 1.1$ \\
\hline $\begin{array}{l}\text { Mean duration of hospital } \\
\text { stays (days) }\end{array}$ & $6.7 \pm 1.9$ \\
\hline MICU stay (day) (\%) & \\
\hline 2 & $12(7.2)$ \\
\hline $3-5$ & $28(16.8)$ \\
\hline $6-7$ & $47(28)$ \\
\hline$>7$ & $79(47.5)$ \\
\hline Complications (\%) & \\
\hline No & $132(79.6)$ \\
\hline Yes & $34(20.4)$ \\
\hline Bladder injury & $5(3)$ \\
\hline PPH & $7(4.2)$ \\
\hline Coagulopathy & $7(4.2)$ \\
\hline Infection & $15(9)$ \\
\hline ICU admission & 166 \\
\hline Delayed hysterectomy $(\%)$ & $4(2.4)$ \\
\hline Re-exploration & $2(1.2)$ \\
\hline Mortality & 0 \\
\hline
\end{tabular}

The mean duration of MICU stay in placenta previa was $6.7 \pm 1.9$ days (range 2-12 days). With complications in 18 cases of which urinary bladder injury (3\%), infection (9\%), $\mathrm{PPH}$ and coagulopathy (4.2\%). The placenta was removed successfully in 141 while 25 cases had caesarean hysterectomy $(2.4 \%)$.

In total 166 cases $26(16.8 \%)$ cases are IUD and still births.

The $5(3 \%)$ cases are very birth weight, 24 cases (14.5\%) are low birth weight babies, $76(45.8 \%)$ cases had NICU admissions followed by $10(6 \%)$ cases with <5 APGAR score. 
Table 3: Fetal outcome in present study.

\begin{tabular}{|lll|}
\hline Outcomes & No. of cases & Percentages $(\%)$ \\
\hline Live births & 147 & 88.5 \\
\hline $\begin{array}{l}\text { IUD and still } \\
\text { births }\end{array}$ & 28 & 16.8 \\
\hline Low birth weight babies $(\mathbf{k g s})$ & \\
\hline <1.5 & 5 & 3 \\
\hline $1.5-2.5$ & 24 & 14.5 \\
\hline$>2.5$ & 130 & 78.5 \\
\hline $\begin{array}{l}\text { NICU } \\
\text { admissions }\end{array}$ & 10 & 6 \\
\hline $\begin{array}{l}\text { APGAR score }<5 \\
\text { after 5 min }\end{array}$ & 65 & 39 \\
\hline $\begin{array}{l}\text { APGAR score }>\mathbf{5} \\
\text { after 5 min }\end{array}$ & 101 & 60.8 \\
\hline
\end{tabular}
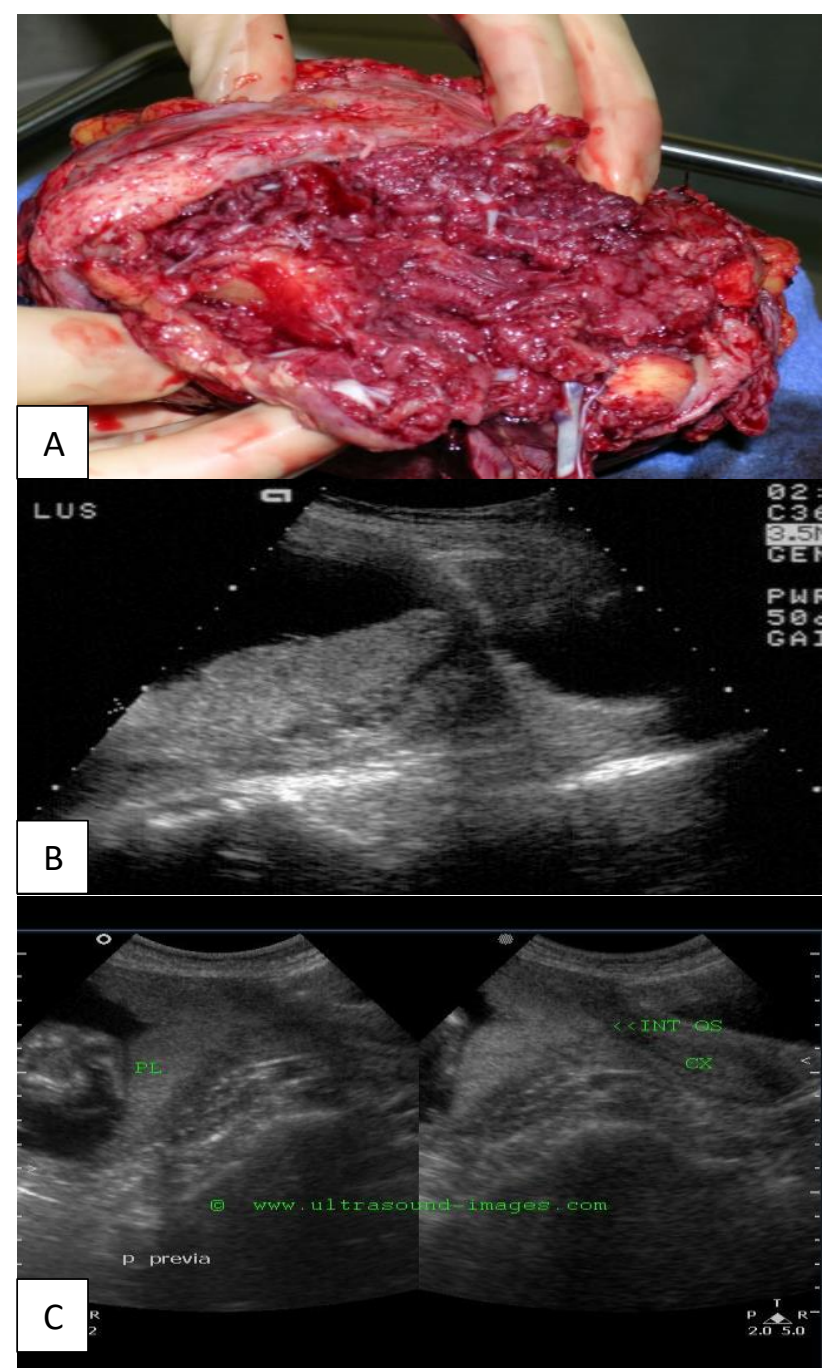

Figure 1 (A, B and C): Operated case of morbid adherent placenta and ultrasound finding of the same.

\section{DISCUSSION}

Morbidly adherent placenta was seen in 5:1000 (0.5\%) deliveries in our hospital over a 2-year period. In 2017, the first national and binational case-control study of morbidly adherent placenta in Australia and New Zealand found an incidence rate of 44.2/100000 women given birth or $0.0442 \% .^{6,7}$ The most cited epidemiological study is that of Miller et al who found in the United States over a period of 10 years (1985-1994) 62 placentas accreta on 155670 births with an incidence rate of $1 / 2510$ births or $0.0398 \% .^{8}$ Recently, Carusi reported that the exact incidence of morbidly adherent placenta is not easy to ascertain, but it is about $1 / 1000$ deliveries and this incidence is increasing along with increasing the risk factors. This lower incidence can be explained by the fact that screening is more effective in developed countries than in low-and middleincome countries. The only certainty is that the incidence of morbidly adherent placenta has increased dramatically in a few decades, and it was shown that this was likely correlated to the increasing rate of cesarean delivery. ${ }^{9}$

The present results revealed that risk factors for morbidly adherent placenta were maternal age, $>35$ years, previous CS $(\geq 2)$, multiparity $(\geq 3)$ and previous history of placenta previa. These results agreed with many authors, Fitzpatrick et al. studied risk factors for morbidly adherent placenta and found that high maternal age, prior caesarean delivery and placenta previa were considered as significant risk factors. Also, another study in 2017 reported that older maternal age, prior CS, placenta previa and high parity were independent risk factors for morbidly adherent placenta. Also, other investigators reported similar results. In Choudhary et al study all patients were multiparous with $84 \%$, in study by Fitzpatrick et al also, concurrent placenta praevia was recorded in $53 \%$ cases, which is lesser compared to $71 \%$ in study by Choudhary et al 2 and $64 \%$ in study by Fizpatrick et al. ${ }^{10-12}$

According to the current findings, blood transfusion was required in all 166 cases of placenta accreta spectrum. A recent study published in 2018 found that $94.7 \%$ of placenta accrete cases required blood transfusion, while another study found that $75.0 \%$ cases required blood transfusion. In these circumstances, blood transfusion should be expected, and in some cases, major transfusion may be required. According to Wright et al the average blood loss for morbidly adherent placenta cases undergoing caesarean hysterectomy was $3000 \mathrm{ml}$, with a mean transfusion requirement of 5 packed red blood cell (PRBC) units. About $41.7 \%$ of women with a recognised diagnosis of placenta accrete had an estimated blood loss of $5000 \mathrm{~mL} .{ }^{13}$ Our findings are similarly consistent with Epstein et al findings' which were based on a study of 77 women with morbidly adherent placenta. The hysterectomy group had a statistically significant greater EBL than the conservative management group (2989 ml vs. $1410 \mathrm{ml}$ ). Our findings are also consistent with other studies in the literature that show that conservative management reduces the requirement for blood transfusions as compared to extirpative management. ${ }^{14}$

The average length of MICU stay in the CS hysterectomy group was 6.7 days, according to our findings. It has been reported that the average MICU stay after a CS 
hysterectomy ranged from 4 to 8 days, which is similar to our data.

Bladder damage was noted as a problem in $3 \%$ of our research participants. Many research back up our findings, stating that problems following a caesarean hysterectomy are more common, with bladder and ureteric injuries being the most common. ${ }^{15}$

In our analysis, the uterus was preserved in $97 \%$ of the instances. Overall, our findings show that cautious management may be beneficial in cases when couples want to continue trying to conceive with the promise of a follow-up. We also discovered that UAE reduced placental vascularity and hastened placental resorption, which is consistent with previous research.

The mortality rate of Placenta Accrete has been reported to be around $7 \%$. In a recent study in Egypt, the death rate in PA cases was reported to be $3.2 \%$. However, a nationwide study in the United States found a mortality rate of $1.0 \%$ in women who had an obstetric hysterectomy, although other studies found mortality rates of $1-6 \%$. Fortunately, no deaths were reported in the current investigation. $^{16}$

In total 166 cases $26(16.8 \%)$ cases are IUD and still births. $5(3 \%)$ cases are very birth weight, 24 cases $(14.5 \%)$ are low birth weight babies $76(45.8 \%)$ cases had NICU admissions followed by $10(6 \%)$ cases with $<5$ APGAR score. In Singh et al study four were stillborn, nine needed NICU transfer and eight had an APGAR score of 9 at 5 min of birth. ${ }^{17}$

Cutting through the placenta and separating the placenta can cause torrential bleeding which is difficult to manage, so this can be avoided in case of morbidly adherent placenta and cost effect reducing the burden of health resources. These cases should be managed in higher centres. Tertiary care centres with all facilities like experienced obstetricians, for adequate blood transplants like blood banks, Neonatal banks, unital care, experienced anesthetists, urologists, RICUs. Expert radiologists to diagnose morbidly adherent placenta should be available. When placenta is in anterior lower uterine segment in cases of previous LSCS, ultrasound and MRI has to be done.

\section{CONCLUSION}

The increased use frequency of CS has been linked to an increase in morbidly adherent placenta. It is possible to make an antepartum diagnosis using suitable radiological tests, and the patient can be saved from a life-threatening postpartum haemorrhage, as well as planned measures to save the uterus.

Funding: No funding sources Conflict of interest: None declared

Ethical approval: The study was approved by the Institutional Ethics Committee

\section{REFERENCES}

1. Silver RM, Landon MB, Rouse DJ, Leveno KJ, Spong CY, Thom EA et al. Maternal morbidity associated with multiple repeat cesarean deliveries. Obstet Gynecol. 2006;107:1226-32.

2. O'Brien JM, Barton JR, Donaldson ES. The management of placenta percreta: conservative and operative strategies. Am J Obstet Gynecol. 1996;175:1632-8.

3. Ajah LO, Eze MI, Dim CC, Ezegwui HU, Nikwo PO, Eluke CC et al. Placenta percreta in a booked multiparous woman with minimal risk factors and challenges of management in low resource setting. Niger J Med. 2012;21:359-60.

4. Belfort MA, Shamsirsaz AA, Fox KA. The diagnosis and management of morbidly adherent placenta. Semin Perinatol. 2018;42:49-58.

5. Warshak CR, Ramos GA, Eskander R, Benirschke K, Saenz CC, Kelly TF et al. Effect of predelivery diagnosis in 99 consecutive cases of placenta accreta. Obstet Gynaecol. 2010;115:65-9.

6. Slaoui A, Talib S, Nah A. Placenta accreta in the department of gynaecology and obstetrics in Rabat, Morocco: case series and review of the literature. Pan Afr Med J. 2019;33:86.

7. Farquhar CM, Li Z, Lensen S, McLintock C, Pollock W, Peek MJ. Incidence, risk factors and perinatal outcomes for placenta accreta in Australia and New Zealand: a case-control study. BMJ Open. 2017;7(10):e017713.

8. Miller DA, Chollet JA, Goodwin TM. Clinical risk factors for placenta previa-placenta accreta. Am J Obstet Gynecol. 1997;177(1):210-14.

9. Carusi DA. The PAS disorders Spectrum: epidemiology and risk factors. Clin Obstet Gynecol. 2018;61(4):733-42.

10. Fitzpatrick KE, Sellers S, Spark P, Kurinczuk JJ, Brocklehurst $\mathrm{P}$ et al. Incidence and risk factors for PAS disorders/increta/Percreta in the UK: a national case-control study. PLoS One. 2012;7(12):e52893.

11. Farquhar CM, Li Z, Lensen S. Incidence, risk factors and perinatal outcomes for PAS disorders in Australia and New Zealand: a case-control study. BMJ Open. 2017;7:e017713.

12. Choudhary D, Nigam A, Yadav R, Choudhary S. Placenta Accreta: Obstetrician's nightmare. A case series of 7 patients. NJOG. 2012;7(3):56-8.

13. Wright JD, Herzog TJ, Shah M, Bonanno C, Lewin $\mathrm{SN}$, Cleary $\mathrm{K}$ et al. Regionalization of care for obstetric hemorrhage and its effect on maternal mortality. Obstet Gynecol. 2010;115:1194-200 .

14. Wong VV, Burke G. Planned conservative management of placenta percreta. J Obstet Gynaecol. 2012;32(5):447-52.

15. Eller AG, Porter TF, Soisson P, Silver RM. Optimal management strategies for PAS disorders. BJOG. 2009;116:648-54.

16. Zakherah MS, Abdel-Aziz M, Othman ER, Abbas AM. Maternal and neonatal outcomes of placenta 
previa and accreta at Assiut women's health hospital, Egypt. Int J Reprod Contracept Obstet Gynecol. 2018;7(8):3024.

17. Singh R, Pradeep Y. Maternal and neonatal outcomes in morbidly adherent placenta: a developing country experience. Trop Doct. 2015;45(3):183-7.
Cite this article as: Veludandi U, Suman BA, Nagamani S, Hothur M. Evaluation of outcome of pregnancy in placenta accreta spectrum. Int J Reprod Contracept Obstet Gynecol 2021;10:3331-5. 